\title{
The impact of the 21 November 2016 epidemic thunderstorm asthma event on general practice clinics in metropolitan Melbourne, Australia
}

\author{
Nicole Hughes, Anna-Lena Arnold, \\ Clare Brazenor, Vanora Mulvenna, \\ Danny Csutoros
}

\section{Background and objective \\ On 21 November 2016, parts of Victoria experienced a devastating epidemic thunderstorm asthma (ETSA) event. The aim of this study was to describe the epidemiology and burden of the 2016 ETSA event at Medicinelnsight-registered general practices in the Melbourne metropolitan area in Victoria, Australia.}

\section{Methods \\ A cross-sectional study was conducted using patient record data from 21-23 November 2016. Codes were developed to identify all patients presenting to Medicinelnsight-registered general practices with asthma during the 2016 ETSA event.}

\section{Results}

During the event, there were 787 more asthma-related encounters to Medicinelnsight general practices than expected, which represented a 7.1-fold increase (605\% increase). Estimates suggest that there were between approximately 8940 and 13,689 more asthma-related encounters than expected across metropolitan Melbourne.

\section{Discussion}

General practices were significantly affected by the 2016 ETSA event. This work highlights the important part that general practices play in responding to ETSA events and the need for these practices to be prepared to respond.
EPIDEMIC THUNDERSTORM ASTHMA (ETSA) describes the sudden onset of asthma in a large number of people and is thought to be caused by a unique combination of high amounts of grass pollen in the air and a certain type of thunderstorm. Although ETSA events are uncommon, they can place considerable pressure on health systems, because they result in near-simultaneous asthma exacerbations in susceptible individuals. ${ }^{1}$

On 21 November 2016, parts of Victoria experienced a devastating ETSA event. This event resulted in widespread and significant strain on the health system, with unprecedented numbers of people calling triple zero, requiring ambulance services and presenting to hospital. ${ }^{1,2}$ The impact of the event has been described in a Victorian Chief Health Officer's report, which summarised that Melbourne and Geelong public hospitals experienced a $672 \%$ increase (3365 more presentations than expected) in respiratory-related emergency department presentations and a 992\% increase in asthma-related admissions in the 30 hours from $6.00 \mathrm{pm}$ on 21 November 2016. ${ }^{1}$ There were 1626 more calls to the Emergency Services Telecommunications Authority (Triple Zero) than forecast. Furthermore, this event resulted in 10 deaths that have been investigated by the Victorian Coroner. ${ }^{3}$ ETSA events have previously occurred in Melbourne, ${ }^{4,5}$ but Victoria's health services, emergency services and the community were not prepared for an event of this scale and intensity. ${ }^{1,6}$

The impact of ETSA events has been primarily described in terms of the demand on hospital systems, including emergency department presentations and admissions. Publications describing the impact of such events on primary care have been more limited. International work from the UK showed that general practices experienced a surge in asthma presentations during and the day after a thunderstorm asthma event in 1994..$^{7,8}$ Following the catastrophic 2016 event in Victoria, the impact on the National Home Doctor Service, NURSE-ON-CALL and Supercare Pharmacies was detailed in a Chief Health Officer's report, which showed increased demand across these services during the event. ${ }^{1}$ Farouque et $\mathrm{al}^{9}$ undertook a qualitative study that showed that general practitioners (GPs) reported a large surge in patient numbers and made a substantial contribution to the emergency response on the evening of 21 November 2016. However, to date, only limited quantitative analysis of the impact of the 2016 event on the primary health sector has occurred.

GPs play a crucial part in the management of emergencies, ${ }^{10,11}$ including acute response and long-term recovery. ${ }^{12}$ GPs' key roles in responding to emergencies are not always recognised, such as in response to the $2009 \mathrm{H} 1 \mathrm{~N} 1$ pandemic, where the learnings suggest 
the role of GPs was underestimated. ${ }^{13}$ Therefore, these authors postulate that significantly more community members than highlighted in impact information to date were affected and sought medical care during the 2016 ETSA event through their GPs.

The aim of this analysis was to estimate the impact of the 2016 ETSA event on general practices in Melbourne metropolitan areas by using data from MedicineInsight-registered general practices, and to add vitally missing information to complete a fuller picture of the impacts of this event. This research will assist primary care planners and clinicians in understanding, with greater clarity, the need that may arise from future events and the importance of driving improvements in asthma management to reduce associated impacts.

\section{Methods}

A cross-sectional study was conducted using MedicineInsight primary care data. MedicineInsight is a general practice data program that extracts de-identified patient health records from clinical information systems (Best Practice and Medical Director ${ }^{14}$ in Australia. A decision was made to describe the impact of the event from 21 through 23 November 2016 , given that impacts were evident in public hospitals for a number of days and the storm hit metropolitan Melbourne at $6.00 \mathrm{pm}$ on 21 November 2016 (a time at which many general practices would have been closed).

The MedicineInsight program collects de-identified data on patient demographics, encounters, diagnoses, prescriptions and pathology tests (but not progress notes). In Victoria, the MedicineInsight program represents approximately $7.1 \%$ of all Victorian general practices (141 of 1990 sites). ${ }^{15}$ Each site may have multiple GPs, and in some cases several practices per site. Based on the number of active MedicineInsight patients in 2018 and the number of people living in Victoria in 2016, MedicineInsight data represents general practice visits by approximately $7.7 \%$ of the population. ${ }^{15}$ Regular patients are defined as those who have at least three consultations in any two consecutive years, in accordance with The Royal Australian College of General Practitioners' definition of 'active' patients. ${ }^{16}$ Analysis was restricted to MedicineInsight sites that were located in the Melbourne metropolitan area $(n=58$ sites). The Melbourne metropolitan area includes 31 local government areas (https://liveinmelbourne.vic. gov.au/discover/melbourne-victoria/ metropolitan-melbourne). In the Melbourne metropolitan area, the MedicineInsight program includes records for approximately $10.1 \%$ of the population (based on 2016 population data).

To estimate the burden of asthma across metropolitan Melbourne, a rudimentary approach was developed to provide an estimate of the overall impact of asthma on general practices. Two methods were used to create an approximate range. The first involved crudely re-scaling the number of encounters from $10.1 \%$ to $100 \%$ coverage by multiplying the number of encounters by 9.901 . The second approach involved weighting the data by local government area (LGA). The rate of asthma presentations was calculated for each LGA for which data was available, then averaged and adjusted by population to obtain the number of presentations in metropolitan Melbourne. This number was then scaled based on MedicineInsight's $10.1 \%$ coverage of practices.

\section{Encounters}

For this research, an encounter was defined as an interaction between a patient and a GP. There is currently no single consistent definition of an 'encounter' for general practice electronic health records in Australia because of several challenges within the clinical information system whenever an electronic health file is opened. For this analysis, the authors attempted to exclude administrative-type encounters by excluding encounters that were classified as 'other' or 'unknown type' in the 'Clinical User Type' dataset; visits that were classified as 'non visit', 'practice admin', 'email' or 'sms' in the
'Visit Type' dataset; and encounters with a 'non-clinical' reason for encounter in the encounter reason dataset. The code used to extract asthma-related reasons for encounters is shown in Appendix 1 (available online only).

\section{Statistics}

Descriptive statistics were used to present the study outcomes, including use of percentages. Data management and analyses were conducted with STATA version 15 and PowerBi.

\section{Ethics}

This study was approved by The

Department of Health and Human Services Research Ethics Committee, reference number: 05/18.

\section{Results}

The characteristics of the patients presenting with an asthma-related encounter to MedicineInsight-registered practices on 21-23 November 2016 are summarised in Table 1 and Figure 1.

From 21 November through 23 November, there were 917 asthmarelated encounters to MedicineInsightregistered practices in metropolitan Melbourne $(21$ November $=124$, 22 November $=538,23$ November $=$ 255 ; Table 2). The proportion of asthmarelated encounters (as a percentage of total encounters) is shown in Table 3.

At MedicineInsight-registered practices on 21 November 2016, there were 77 more asthma-related encounters than expected (based on the 2011-15 five-year Monday daily average of 47 encounters), on 22 November 2016 there were 496 more asthma-related encounters than expected, and on 23 November 2016 there were 214 more asthma-related encounters than expected. Over the three days, there were 787 more asthmarelated encounters than expected, which represented a 7.1-fold increase in asthmarelated encounters, or a $605 \%$ increase (Table 3).

Figure 2 shows the number of asthma-related encounters to a MedicineInsight-registered practice over the 10-year period from 2009 to 2018. 
Table 1. Characteristics of patients presenting with an asthma-related encounter to Medicinelnsight-registered sites on 21-23 November 2016 in metropolitan Melbourne, Victoria, Australia

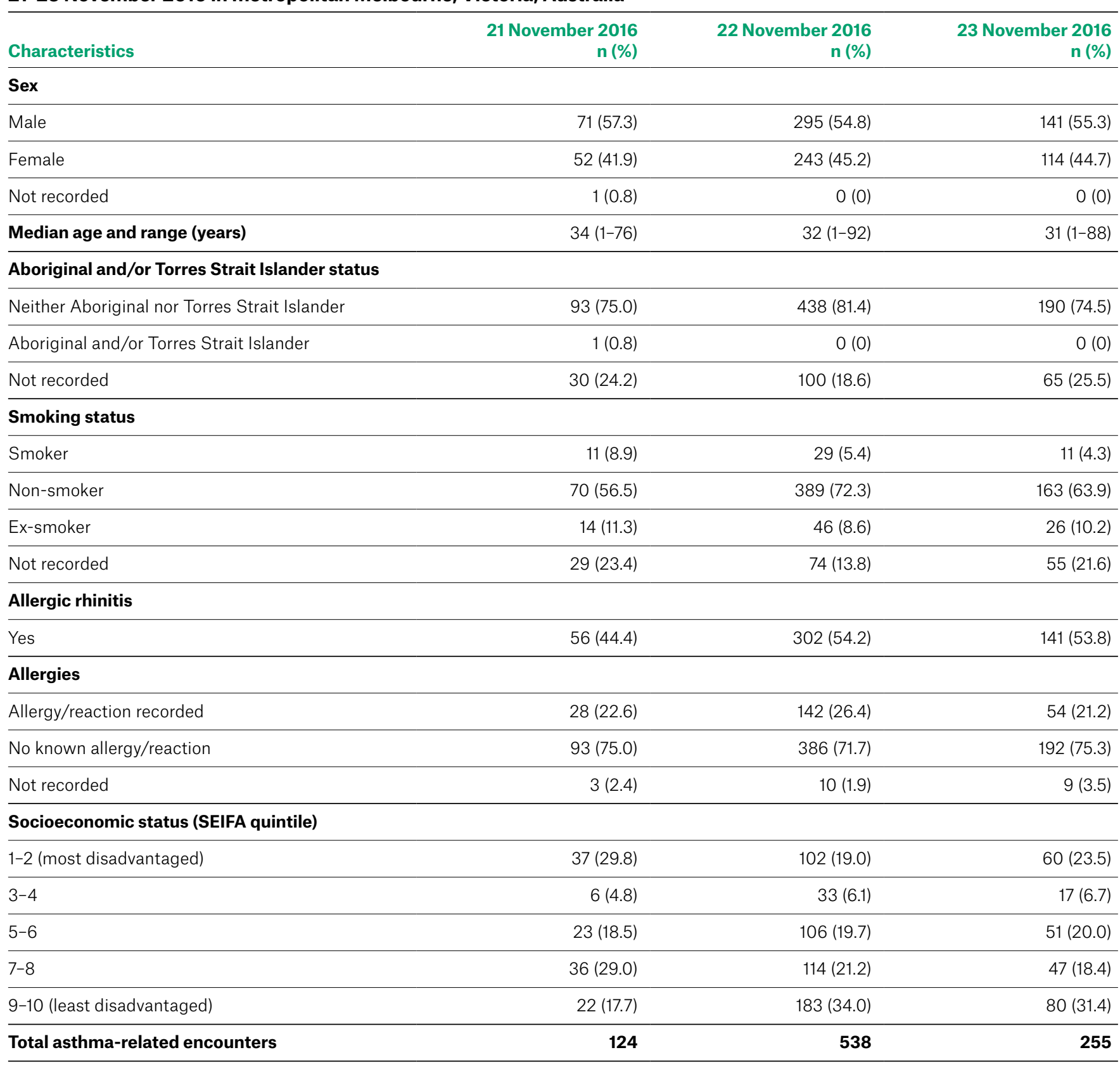

${ }^{*} n$ (\%) used for all data except median age and range

SEIFA, Socio-Economic Indexes for Areas

\section{Estimating the burden across the Melbourne metropolitan area}

As detailed, two methods were used to estimate the number of people who attended a general practice site for asthma in the Melbourne metropolitan area during the November 2016 ETSA event.
Using the first method, it is estimated that approximately 9080 people went to a general practice for asthma between 21 and 23 November 2016 in the Melbourne metropolitan area.

Using the second method, the rate of asthma-related encounters by LGAs in the Melbourne metropolitan area was estimated to range from $0.001 \%$ to $0.014 \%$ (average $0.004 \%$ ) on 21 November 2016, from $0.002 \%$ to $0.038 \%$ (average $0.016 \%$ ) on 22 November 2016, and from $0.001 \%$ to $0.023 \%$ (average $0.008 \%$ ) on 
23 November 2016. This equated to approximately 185 people for the whole of the Melbourne metropolitan area on 21 November 2016, 803 on 22 November 2016 and 381 on 23 November 2016. MedicineInsight is estimated to cover approximately $10.1 \%$ of all general practice sites in the Melbourne metropolitan area. Based on this, it is estimated that approximately 1870 people went to a general practice site for their asthma on 21 November 2016, 8113 on 22 November and 3845 on 23 November. Over the three days, the total number of people presenting to general practice sites with asthma was estimated to be 13,829 .

These methods suggest that between approximately 9080 and 13,829 people attended a general practice for asthma across metropolitan Melbourne during the 2016 ETSA event (8940-13,689 more

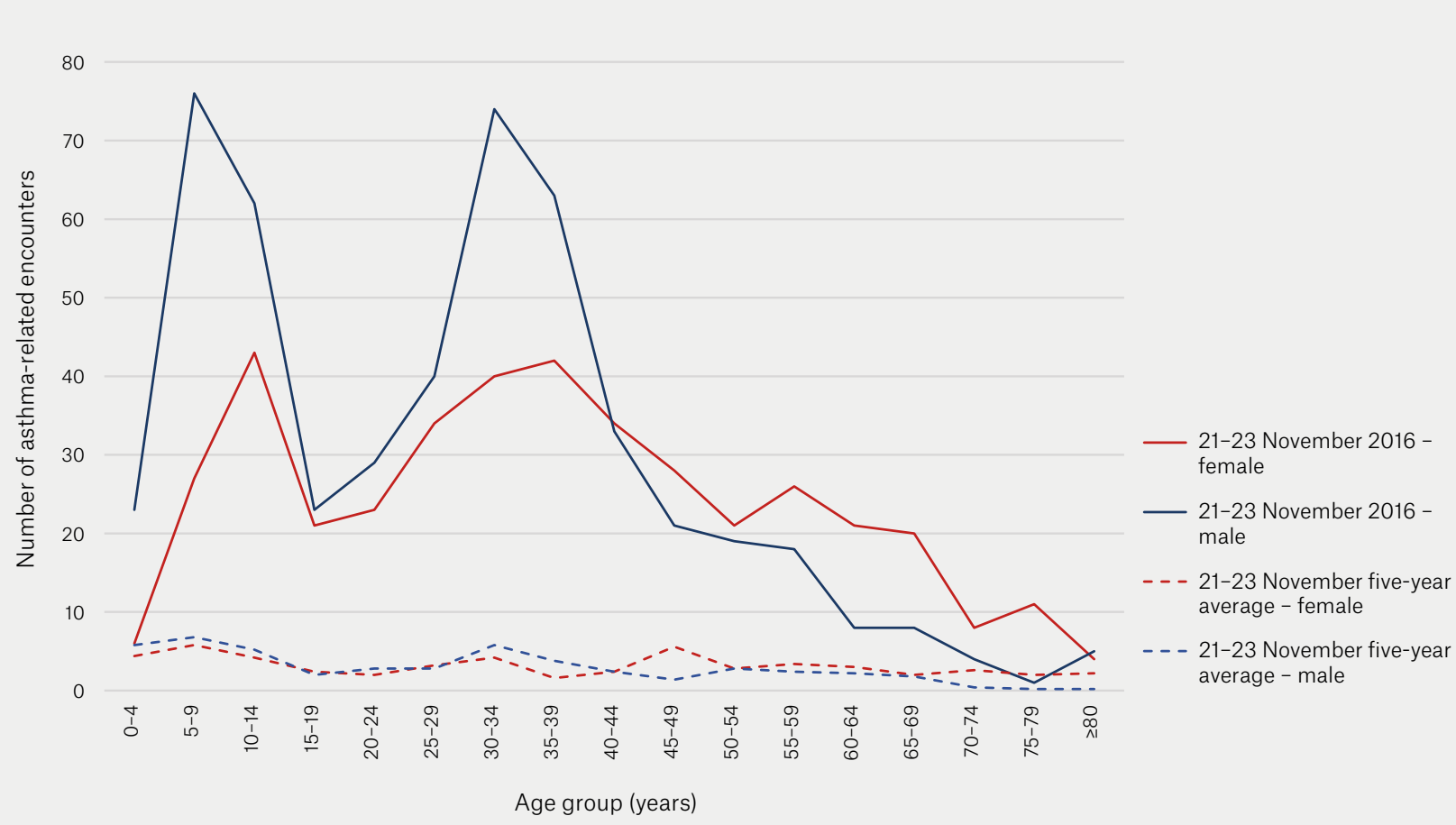

Figure 1. Asthma-related encounters to Medicinelnsight-registered sites, by age and sex, on 21-23 November 2016, compared with five-year average (2011-15)

Table 2. Asthma-related encounters at Medicinelnsight-registered sites during the event, compared with five-year daily average (2011-15)

\begin{tabular}{lrrrrr}
\hline & $\begin{array}{r}\text { Five-year } \\
\text { Monday } \\
\text { asthma } \\
\text { average }\end{array}$ & $\begin{array}{r}\text { 22 November } \\
21 \text { November } \\
2016\end{array}$ & $\begin{array}{r}\text { Five-year } \\
\text { Tuesday } \\
\text { asthma } \\
\text { average }\end{array}$ & $\begin{array}{r}\text { Five-year } \\
23 \text { November } \\
2016\end{array}$ & $\begin{array}{r}\text { Wednesday } \\
\text { asthma average }\end{array}$ \\
\hline Asthma-related encounters & 124 & 47 & 538 & 42 & 255
\end{tabular}

Table 3. Proportion of asthma-related encounters (as a percentage of total encounters) at Medicinelnsight-registered sites during the event and 2011-15 five-year daily average

\begin{tabular}{|c|c|c|c|c|c|}
\hline & $\begin{array}{r}21 \text { November } \\
2016\end{array}$ & $\begin{array}{r}22 \text { November } \\
2016\end{array}$ & $\begin{array}{r}23 \text { November } \\
2016\end{array}$ & $\begin{array}{r}\text { Event (21-23 } \\
\text { November 2016) }\end{array}$ & $\begin{array}{r}\text { Five-year } \\
\text { November daily } \\
\text { average }\end{array}$ \\
\hline $\begin{array}{l}\text { Proportion of asthma- } \\
\text { related encounters }\end{array}$ & $1.30 \%$ & $6.10 \%$ & $3.20 \%$ & $3.50 \%$ & $0.74 \%$ \\
\hline
\end{tabular}


encounters than expected on the basis of five-year daily averages).

\section{Discussion}

On 21 November 2016, a thunderstorm occurred in Melbourne in the late afternoon, and from $6.00 \mathrm{pm}$, emergency services experienced unprecedented increased demand. General practices in the Melbourne metropolitan area also experienced a considerable impact from the event, with an estimated $605 \%$ increase in asthma-related encounters from 21 through 23 November 2016. GPs are an important part of the primary healthcare system in Australia, and this research provides crucial evidence of their important role in responding to public health emergencies. Furthermore, climate change is affecting thunderstorms and weather patterns, and with growing evidence regarding impacts of climate change on allergies and asthma, ${ }^{17}$ the role of GPs in the prevention and management of thunderstorm asthma will be increasingly important.
General practices generally have less capacity than emergency departments to increase the number of patient consultations per day as a result of the appointment structure; however, data from the November 2016 ETSA event show that GPs re-prioritised their caseloads to accommodate the increased demand from individuals presenting with asthma. Melbourne and Geelong hospital emergency departments experienced significant strain in managing the extra 3365 more presentations than expected, and the role of GPs in seeing an extra 8940-13,689 asthma-related cases is likely to have protected the emergency departments from further strain.

Interestingly, the characteristics of people affected during the 2016 event across both hospital presentation and general practice presentation datasets showed some similarities. Across both datasets, there is a peak in boys aged 5-9 years and men aged 30-34 years. ${ }^{1}$ Sex differences appear in asthma incidence, prevalence, severity, exacerbation rates, hospitalisation and mortality worldwide, ${ }^{18}$ and research has shown that in an adult population, exacerbation rate, hospitalisation rate and mortality are higher in women when compared with men. ${ }^{19}$ Female sex can also be a risk factor for severe exacerbations. ${ }^{20}$ There are a number of potential rationales for the different characteristics of people affected by the 2016 ETSA event such as a potential sex difference in thunderstorm asthma impacts, or a greater proportion of men being exposed to the environmental conditions on 21 November 2016 than women.

Although this event affected many people who did not have an asthma diagnosis, a large number of those who were admitted to hospital and all those admitted to intensive care had a diagnosis of asthma. ${ }^{2}$ Of the 10 people who died, all had an asthma diagnosis, and for many their asthma was poorly controlled or uncontrolled. ${ }^{3}$ GPs are key to supporting improved control and management of asthma and hay fever,

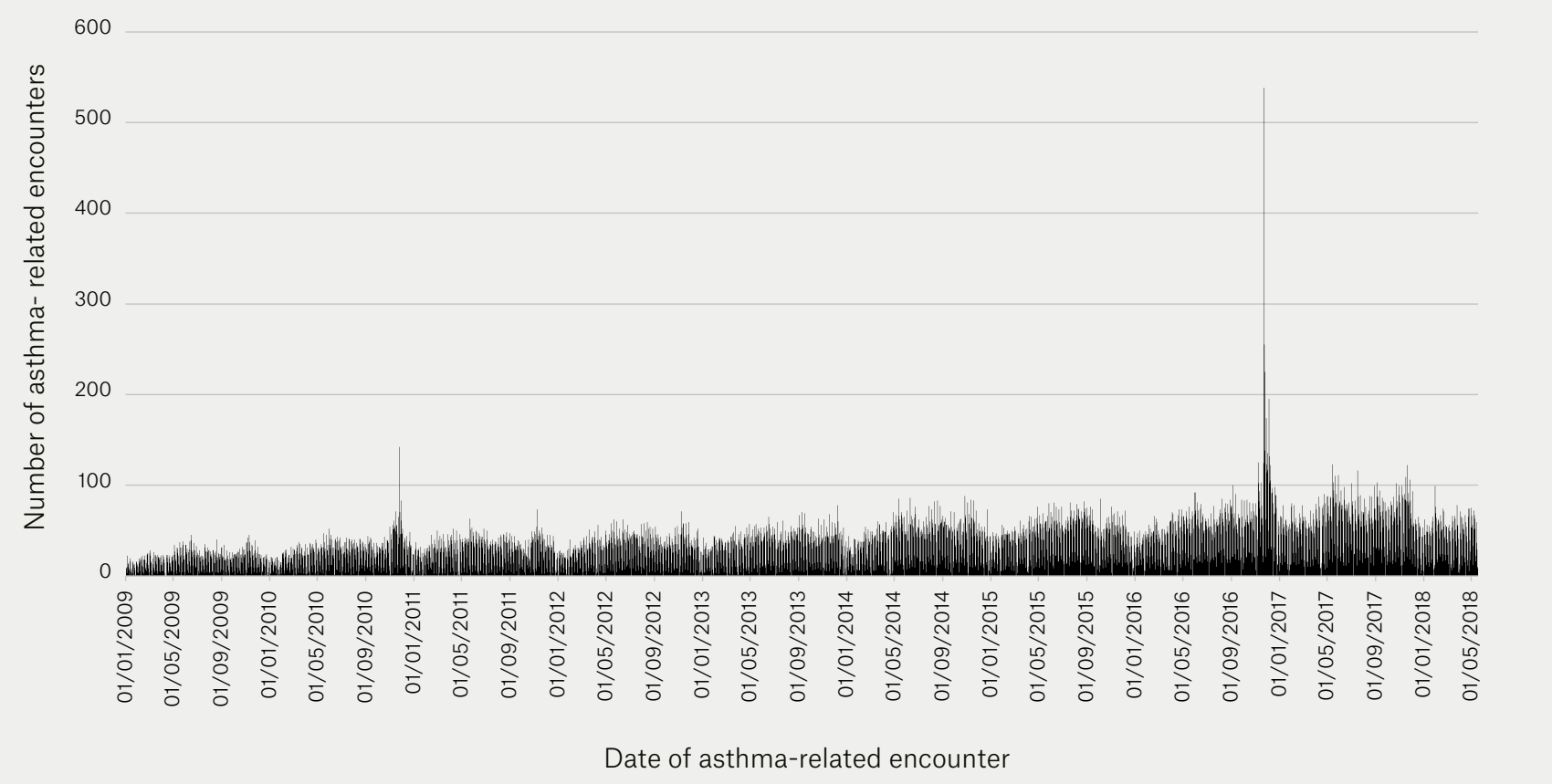

Figure 2. Daily number of asthma-related encounters presenting to Medicinelnsight-registered practices with an asthma-related encounter from 01/01/2009 to 18/05/2018, metropolitan Melbourne, Victoria, Australia 
which is critical in reducing the impacts of future events. Despite significant research into management and effective therapies, individual achievement of good asthma management is elusive. ${ }^{21}$ Promisingly, Australian and Victorian data suggest that there are ongoing improvements in the primary healthcare sphere through preventive measures such as medications and asthma action planning. ${ }^{22}$ Furthermore, GPs are responsible for managing patients with complex presentations and reducing the impact on hospitals and other tertiary treatment centres through prevention, early management and complex care. This work shows the important role that general practices play in public health emergencies. Together with their work to improve management of asthma and hay fever, GPs will continue to play a pivotal role in the management of thunderstorm asthma in the future.

\section{Limitations}

Data used in this research have some limitations, including their dependency on the accuracy, quality and completeness of entry into the clinical information system.

It is likely that the analysis based on encounters is an underestimate of the total number of people presenting with asthma to general practices in the metropolitan Melbourne area. Analysing the encounter dataset only excludes patients for whom asthma was only recorded in other parts of the clinical information system (eg diagnosis or treatment sections). The estimations of overall burden must be interpreted with an understanding of a number of limitations in the methods, including the gross upscale, the assumption of uniform encounters across sites and the inability to identify people who may visit multiple GPs, resulting in potential duplication of encounters. Furthermore, these data have no way of showing if clinics reached capacity and turned people away, or if there were changes to opening hours or booking practices due to the high numbers of asthma presentations. Demographic data within the MedicineInsight dataset have numerous similarities with overall population data ${ }^{15}$ for the metropolitan Melbourne area, which is why a decision was made to use the methods detailed to estimate the number of people presenting to general practice sites during the November 2016 ETSA event.

\section{Conclusion}

GPs are an important part of the health sector, and they were significantly affected by the 2016 ETSA event in Victoria. This work highlights the need for further understanding about how best to prepare and support general practices to manage people with asthma and hay fever and to respond to ETSA events.

\section{Authors}

Nicole Hughes MPH, BPhysio (Hons), Manager of Investigation and Response, Victorian Department of Health, Melbourne, Vic

Anna-Lena Arnold MPhil, MSc, BSc, Senior Epidemiologist, Victorian Department of Health, Melbourne, Vic

Clare Brazenor MSocSci, MGeomS, BGeomE, Principal Analytics Manager, Victorian Department of Health, Melbourne, Vic

Vanora Mulvenna MEnv, BSci (Hons), Manager of Climate and Health, Victorian Department of Health, Melbourne, Vic

Danny Csutoros MBBS, MPH, FAFPHM, Senior Medical Advisor, Victorian Department of Health, Melbourne, Vic

Competing interests: None.

Funding: This research was funded by the Victorian Department of Health and Human Services.

Provenance and peer review: Not commissioned, externally peer reviewed.

Correspondence to:

nicole.m.hughes@health.vic.au

\section{Acknowledgements}

The authors acknowledge Dr Kara Martin for her biostatistical input.

\section{References}

1. Department of Health and Human Services Victoria. The November 2016 Victorian epidemic thunderstorm asthma event: An assessment of the health impacts. The Chief Health Officer's report. Melbourne, Vic: DHHS, 2017.

2. Thien F, Beggs PJ, Csutoros D, et al. The Melbourne epidemic thunderstorm asthma event 2016: An investigation of environmental triggers, effect on health services, and patient risk factors. Lancet Planet Health 2018;2(6):e255-63. doi: 10.1016/S2542-5196(18)30120-7.

3. The Coroners Court of Victoria at Melbourne. Finding into death with inquest. Court reference: COR 2016 5533. Southbank, Vic: Coroners Court of Victoria, 2018.

4. Bellomo R, Gigliotti P, Treloar A, et al. Two consecutive thunderstorm associated epidemics of asthma in the city of Melbourne. The possible role of rye grass pollen. Med J Aust 1992;156(12):834-37. doi: 10.5694/j.1326-5377.1992.tb136994.x.

5. Erbas B, Akram M, Dharmage SC, et al. The role of seasonal grass pollen on childhood asthma emergency department presentations. Clin Exp Allergy 2012;42(5):799-805. doi: 10.1111/j.13652222.2012.03995.x.

6. Inspector General for Emergency Management. Review of the response to the thunderstorm asthma event of 21-22 November 2016 - Final Report. Melbourne, Vic: Department of Justice, 2017.

7. Higham J, Venables K, Kupek E, Bajekal M. Asthma and thunderstorms: Description of an epidemic in general practice in Britain using data from a doctors' deputising service in the UK. J Epidemiol Community Health 1997;51(3):233-38. doi: 10.1136/jech.51.3.233.

8. Hajat S, Goubet SA, Haines A. Thunderstormassociated asthma: The effect on GP consultations. Br J Gen Pract 1997;47(423):639-41.

9. Farouque AS, Walker R, Erbas B. Thunderstorm asthma epidemic - Management challenges experienced by general practice clinics. J Asthma 2021;58(4):423-29. doi: 10.1080/02770903.2019.1708097.

10. Ramanayake RP, Ranasingha S, Lakmini S. Management of emergencies in general practice: Role of general practitioners. J Family Med Prim Care 2014;3(4):305-08. doi: 10.4103/22494863.148089.

11. Burns PL, Aitken PJ, Raphael B. Where are general practitioners when disaster strikes? Med J Aust 2015;202(7):356-58. doi: 10.5694/mja14.00477.

12. The Royal Australian College of General Practitioners. Managing emergencies and pandemics in general practice: A guide for preparation, response and recovery. East Melbourne, Vic: RACGP, 2013.

13. Australian Government Department of Health and Ageing. Review of Australia's health sector response to pandemic (H1N1) 2009: Lessons identified. Canberra, Vic: Department of Health and Ageing, 2011.

14. NPS MedicineWise. Medicinelnsight data book version 2.1. Sydney, NSW: NPS MedicineWise, 2018.

15. Busingye D, Gianacas C, Pollack A, et al. Data resource profile: Medicinelnsight, an Australian national primary health care database. Int J Epidemiol 2019;48(6):1741-41h. doi: 10.1093/ije/ dyz147.

16. The Royal Australian College of General Practitioners. Standards for general practices. 5th edn. East Melbourne, Vic: RACGP, 2017.

17. Beggs P. Impacts of climate change on allergens and allergic diseases. Cambridge, UK: Cambridge University Press, 2016.

18. Pignataro FS, Bonini M, Forgione A, Melandri S, Usmani OS. Asthma and gender: The female lung. Pharmacol Res 2017;119:384-90. doi: 10.1016/j. phrs.2017.02.017.

19. Melero Moreno C, López-Viña A, García-Salmones Martín M, et al. Factors related with the higher percentage of hospitalizations due to asthma amongst women: The FRIAM study. Arch Bronconeumol 2012;48(7):234-39. English, Spanish. doi: 10.1016/j.arbres.2012.02.008.

20. O'Connor RD, Bleecker ER, Long A, et al. Subacute lack of asthma control and acute asthma 
exacerbation history as predictors of subsequent acute asthma exacerbations: Evidence from

managed care data. J Asthma 2010;47(4):422-28.

doi: 10.3109/02770901003605332.

21. Price D, David-Wang A, Cho SH, et al. Time for a new language for asthma control: Results from REALISE Asia. J Asthma Allergy 2015;8:93-103. doi: 10.2147/JAA.S82633.

22. Australian Institute of Health and Welfare. Asthma in Australia 2011. Asthma series no. 4 cat. no. ACM 22. Canberra, ACT: AlHW, 2011. 